J. Amer. Soc. Hort. Sci. 118(2):269-273. 1993.

\title{
Chilling of Endodormant Peach Propagules: V. Comparisons between Seeds, Seedlings, and Cuttings
}

\author{
James W. Frisby ${ }^{1}$ and Schuyler D. Seeley ${ }^{2}$ \\ Plants, Soils, and Biometeorology Department, Utah State University, Logan, UT 84322-4820 \\ Additional index words. Prunus persica, temperature responses, dormancy
}

\begin{abstract}
We determined whether the chilling process (endodormancy release) was similar in peach [Prunus persica (L.) Batch cv. Johnson Elberta] seeds, seedlings (near normal to physiologically dwarfed), and mature plants (cuttings) by comparing correlation coefficients of various growth measurements following similar chilling treatments. Seed germination (10 days after forcing at 20C) and seedling emergence (15 days after forcing in the greenhouse) correlated highly with leaf and shoot growth (56 days of growth) of seedlings and terminal shoot growth of cuttings (13 days after forcing). The correlations were higher for germination than for emergence. Initial (first season) seedling growth correlated poorly with germination, emergence, budbreak, and growth of seedlings (second season) and shoot growth of cuttings. Budbreak and growth of seedlings correlated highly with shoot growth of cuttings. The abnormal leaf problem, which can cause apex abortion (common with initial seedling growth), confounded correlations with initial seedling growth. Yet, the abnormal leaf problem did not hinder correlations with the second seasons growth. Good relationships between the chilling mechanisms that promoted germination, emergence, budbreak, and growth of seedlings and shoot growth of cuttings existed, but were dependent on what was measured and when the measurement was taken. Germination (forced at 20C) was the most accurate indicator of the seed chilling status for comparisons with the responses of the other propagules.
\end{abstract}

Seeds are often used to study dormancy. Seeds and buds of the same species (cultivar) reportedly have similar chilling requirements (Chang and Werner, 1984; Pasternak-Orawiec and Powell, 1983a, 1983b; Westwood and Bjornstad, 1968). However, these experiments involved relatively few chilling treatments. We investigated the relationships between seed germination, seedling emergence, initial seedling growth, budbreak, and growth of seedlings and shoot growth of mature plants after marginal and optimal chilling treatments. This paper summarizes our findings concerning these relationships.

\section{Materials and Methods}

We compared the chilling responses of endodormant seeds (Frisby and Seeley, 1993a, 1993b), seedlings [physiologically dwarfed to near normal (Frisby and Seeley, 1993c)], and cuttings (Frisby and Seeley, 1993d) of 'Johnson Elberta' peach. Details of the experimental designs and results are found in the respective papers. The materials and methods are summarized below.

Germination and emergence. Moist seeds (five replications of 10 seeds) were subjected to seven isothermal temperatures $(0,2,4$, $6,8,10$, and $14 \mathrm{C})$ for five durations $(20,30,40,50$, and 60 days). Germination was recorded after forcing for $0,5,10$, and 15 days at 20C. Emergence was recorded after forcing for 5, 10, 15, 20, and 25 days under greenhouse conditions.

Initial seedling growth. After 56 days in the greenhouse, seedlings were harvested and growth was measured. These were the seedlings from the emergence experiment.

Seedlings. Seedlings were obtained by a short seed stratification treatment ( 33 days at $4 \mathrm{C}$ ). Germinated seeds were grown in the greenhouse and divided into four types determined by primary

Received for publication 4 Feb. 1992. Accepted for publication 1 Sept. 1992. This report is based, in part, on research conducted and supported as part of SAES Western Regional Research Project W-130. Utah Agr. Expt. Sta. J. Paper no. 4266. The use of trade names does not imply endorsement of the products used nor criticism of similar ones not mentioned. The cost of publishing this paper was defrayed in part by the payment of page charges. Under postal regulations, this paper therefore must be hereby marked advertisement solely to indicate this fact. Graduate Research Assistant.

${ }^{2}$ Professor. stem size and lateral shoot growth (severely physiologically dwarfed to near normal). Seedlings (three single-seedling replications) were subjected to four temperatures $(2,7,10$, or 14C) for the same durations as the seeds. Terminal shoot growth andlateral budbreak were recorded after 17 days of forcing in the greenhouse. Seedlings were harvested (after 64 days), and growth was measured.

Cuttings. Terminal cuttings (200 to $250 \mathrm{~mm}$ ) were collected from mature trees in the fall. Six single cutting replications were subjected to the same seven isothermal temperatures as the seeds for four durations $(20,34,48$, and 62 days). Similar cuttings were treated with several concentrations of gibberellic acid (GA,) (0 to $1.0 \mathrm{~mm}$ ) before forcing. Cuttings were forced in water-filled test tubes in the greenhouse. Terminal shoot growth was recorded after forcing for $6,8,13,15$, and 20 days.

These experiments all had significant interactions between the treatment duration and temperature. The averages from the interactions were used to compare the different plant materials with each other using linear regression. When exact combinations of treatment duration and temperature were not used in all experiments, similar treatments were used. These changes included using the $7 \mathrm{C}$ treatment of the seedling experiment (second season) in place of the $6 \mathrm{C}$ treatment and the 34,48 , and 62 day durations of the cutting experiment in place of the 30,50, and 60 day durations.

Other differences between the experiments that could affect correlations are explained in the results section. Not all possible correlations between the experiments are presented. We show only the highest correlations obtained using similar measurements. If similar correlations were obtained that required more measurements (additional forcing times or treatments), then only the simpler measurements are presented.

\section{Results and Discussion}

The responses of each type of plant material to the chilling treatments are reported in Frisby and Seeley (1993a, 1993b, 1993c, 1993d). In general, temperature treatments between 0 and 10C, especially between 2 and $8 \mathrm{C}$, effectively overcame endodormancy and promoted seed germination, seedling emergence, initial seedling growth, budbreak, and growth of seedlings and cuttings (Frisby and Seeley, 1993b). Generally, initial responses occurred 
Table 1. A matrix of correlation coefficients comparing peach seed ('Johnson Elberta') germination (after 10 days' forcing) and seedling emergence (after 15 days' forcing) with the responses of other propagules after similar chilling treatments.

\begin{tabular}{llcr}
\hline \hline \multirow{2}{*}{ Experiments } & \multicolumn{1}{c}{ Measurements } & \multicolumn{2}{c}{ Correlation coefficient $(r)$} \\
\cline { 3 - 4 } Cuttings & Shoot growth (13 days) & ${\underline{0.92^{* * *}}}^{*}$ & $\underline{0.85^{* * *}}$ \\
& Shoot growth (17days) & $\underline{0.87^{* * *}}$ & $0.80^{* *}$ \\
& Lateral budbreak & $0.83^{* * *}$ & $0.74^{* * *}$ \\
& Leaf dry wt (64 days) & $\underline{0.94}^{* * *}$ & $0.80^{* * *}$ \\
& Shoot dry wt & $\underline{0.95}^{* * *}$ & $\underline{0.88^{* * *}}$ \\
Initial seedling growth & Stem length (56 days) & $0.62^{* * *}$ & $0.55^{* * *}$ \\
& Lateral shoot length & $-0.19^{\text {Ns }}$ & $0.02^{\text {Ns }}$ \\
& Normal leaf area & $0.62^{* * *}$ & $0.57^{* * *}$ \\
& Abnormal leaf area & $-0.53^{* * *}$ & $-0.50^{* *}$ \\
& & & \\
\end{tabular}

Days of forcing or growth in the greenhouse in parenthesis.

Correlations for underlined values explained $>70 \%$ of the variability.

${ }^{\text {NS, }, * * * * *}$ Nonsignificant or significant at $P=0.01$ or 0.001 , respectively.

Table 2. A matrix of correlation coefficients comparing primary stem length, lateral shoot length, normal and abnormal leaf area of initial peach seedling ('Johnson Elberta') growth (first season, 56 days) with the responses of other propagules after similar chilling treatments.

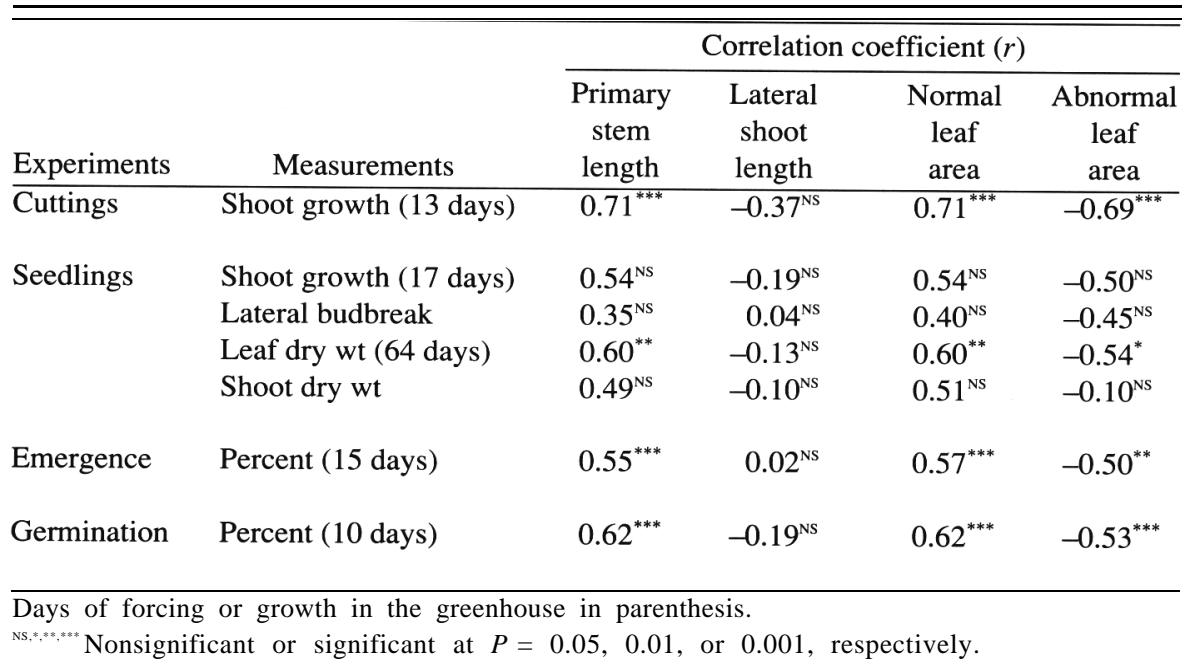

when the plant materials were chilled for 30 to 40 days at effective chilling temperatures.

The chilling requirement of 'Elberta' peach flower buds is reported to be 37 days at 6C [880 chill units (Richardson et al., 1974). While a minimal vegetative chilling requirement was met for 'Johnson Elberta' peach with -40 days of chilling, additional chilling significantly enhanced responses. These very large differences were not expected. The chilling requirement for vegetative growth of 'Johnson Elberta' peach appears to be 50 to 60 days (1200 to 1440 chill units) or more. These results agree with observations in warm climates that 'Elberta' peach flower buds require significantly less chilling than vegetative buds; hence, flowering can occur without simultaneous leaf and shoot growth (Weinberger, 1950; 1956). This difference is more obvious in peach, which has separate simple flower and leaf buds, but also occurs in mixed apple buds (del Real-Laborde, 1987). In addition, chilling that promoted vegetative growth of 'Johnson Elberta' peach occurred at a wider optimum range of temperatures (2 to SC) than reported by Richardson et al. (1974) for 'Elberta' flower buds (5 to $7 \mathrm{C}$ ).

The highest correlation between germination and emergence involved germination after 10 days forcing and emergence after 15 days forcing (Frisby and Seeley, 1993a), which also resulted in the highest correlations with responses of the other experiments (data not presented). Yet, germination after 10 days of forcing correlated about the same as germination averaged over the forcing times.

The three-way interaction between the four seedling types (severely dwarfed to near normal), treatment duration, and treatment temperature of the seedling experiment was not significant (Frisby and Seeley, 1993c). Therefore, the average responses of these four groups were used in comparisons with results from the other experiments.

The mature cutting experiment examined the effects of chilling duration, forcing time, and GA, concentration on terminal shoot growth. The highest correlations involved terminal shoot growth with 13 days of forcing and with no GA, treatment (data not presented). However, the relationship was similar to the correlation involving shoot growth averaged over the forcing times and GA, treatments.

Correlation coefficients involving linear regressions for the experiments are given in Tables 1 through 4 . Graphs of comparisons that explained $270 \%$ of the variability $\left(r^{2} \geq 0.70\right)$, using linear 
Table 3. A matrix of correlation coefficients comparing lateral bud break (per centimeter) and terminal shoot growth (after 17 days' forcing) and leaf and shoot dry weight (after 64 days' growth) of peach seedlings ('Johnson Elberta') with the responses of other propagules after similar chilling treatments.

\begin{tabular}{|c|c|c|c|c|c|}
\hline \multirow[b]{2}{*}{ Experiments } & \multirow[b]{2}{*}{ Measurements } & \multicolumn{4}{|c|}{ Correlation coefficient $(r)$} \\
\hline & & $\begin{array}{l}\text { Shoot } \\
\text { growth }\end{array}$ & $\begin{array}{c}\text { Lateral } \\
\text { bud } \\
\text { break }\end{array}$ & $\begin{array}{l}\text { Leaf } \\
\text { dry wt }\end{array}$ & $\begin{array}{l}\text { Shoot } \\
\text { dry wt }\end{array}$ \\
\hline Cuttings & Shoot growth (13 days) & $0.80^{*}$ & $\underline{0.93}^{* * *}$ & $0_{0.98^{* * *}}$ & $0.97^{* * *}$ \\
\hline \multirow[t]{4}{*}{$\begin{array}{l}\text { Initial seedling } \\
\text { growth }\end{array}$} & Stem length ( 56 days) & $0.54^{\mathrm{NS}}$ & $0.38^{\mathrm{NS}}$ & $0.60^{* *}$ & $0.49^{\mathrm{NS}}$ \\
\hline & Lateral shoot length & $-0.19^{\mathrm{NS}}$ & $-0.04^{\mathrm{NS}}$ & $-0.01^{\mathrm{NS}}$ & $-0.10^{\mathrm{NS}}$ \\
\hline & Normal leaf area & $0.54^{\mathrm{NS}}$ & $0.40^{\mathrm{NS}}$ & $0.60^{* *}$ & $0.51^{\mathrm{NS}}$ \\
\hline & Abnormal leaf area & $-0.50^{\mathrm{NS}}$ & $-0.45^{\mathrm{NS}}$ & $-0.54^{*}$ & $-0.39^{\mathrm{NS}}$ \\
\hline Emergence & Percent ( 15 days) & $0.80^{* *}$ & $0.74^{* * *}$ & $0.80^{* * *}$ & $\underline{0.88}^{* * *}$ \\
\hline Germination & Percent (10 days) & $\underline{0.87}^{* * *}$ & $0.83^{* * *}$ & $\underline{0.94}^{* * *}$ & $\underline{0.95}^{* * *}$ \\
\hline
\end{tabular}

Days of forcing or growth in the greenhouse in parenthesis.

Correlations for underlined values explained $>70 \%$ of the variability.

${ }^{\text {NS }, *, *, * * *}$ Nonsignifcant or significant at $P=0.05,0.01$, or 0.001 , respectively.

or polynomial regression, are shown in the figures.

Germination and emergence correlated highly with terminal shoot growth of cuttings (Table 1, Fig. 1). The response was linear for germination and curvilinear for emergence. Comparisons between emergence and shoot growth were meaningful only after emergence exceeded 40\%. Germination correlated highly with terminal shoot growth, lateral budbreak, and leaf and shoot dry weight of seedlings (Fig. 2). The correlation for lateral budbreak was best fit by polynomial regression with meaningful comparisons at germination rates between $0 \%$ and $60 \%$. The correlations between germination and leaf or shoot dry weight were very high and linear. Emergence correlated highly with seedling shoot and leaf dry weight (Fig. 2). These correlations were polynomial and useful at seedling emergences $>20 \%$. Germination and emergence correlated poorly with initial seedling growth.

Initial seedling growth also correlated poorly with budbreak or growth of seedlings (second season) or growth of cuttings after

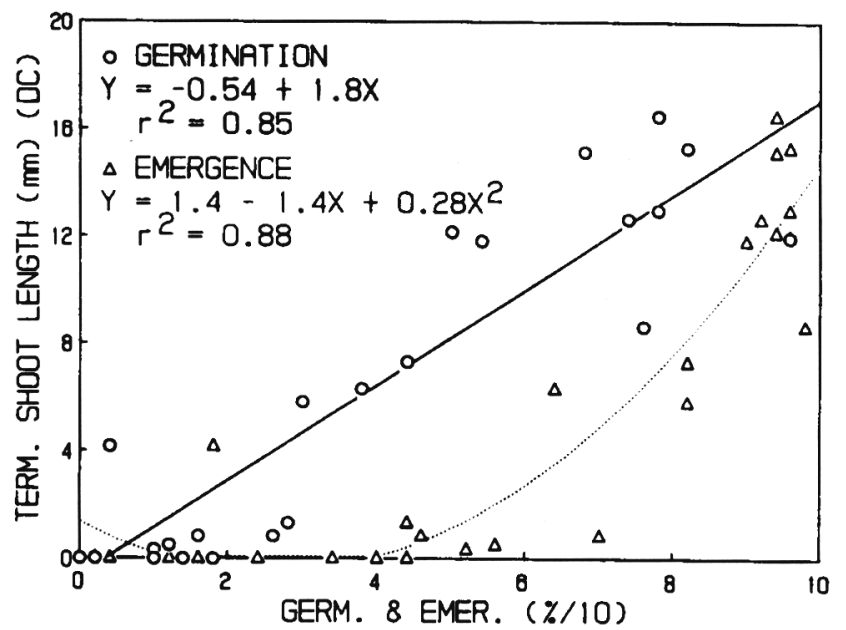

Fig. 1. Correlations between germination (after 10 days' forcing) and emergence (after 15 days' forcing) of 'Johnson Elberta' peach seeds with terminal shoot growth of mature cuttings [DC (after 13 days' forcing)] from 'Johnson Elberta' peach trees after similar chilling treatments. similar chilling treatments (Table 2). Abnormal leaf development made it difficult to assess initial primary stem growth (Frisby and Seeley, 1993b; Wang and Beardow, 1968). Our data suggest that the abnormal leaf condition confounded correlations with other seed and bud responses. Still, the abnormal leaf condition is overcome by additional stratification or chilling of the seed or physiologically dwarfed seedling (Davidson, 1934; Flemion, 1959). Abnormal leaf development does not seem to be directly related to delayed foliation (Chandler et al., 1937) as suggested by some (see Pollock, 1962).

Lateral budbreak and leaf and shoot growth of seedlings correlated highly with terminal shoot growth of cuttings (Table 3). The response was curvilinear for lateral budbreak and linear for shoot and leaf dry weights (Fig. 3). Interestingly, terminal shoot growth (17 days of forcing) of peach seedlings (Table 3 ) did not correlate as highly with the responses of the propagules of the other

Table 4. A matrix of correlation coefficients comparing terminal shoot growth (after 13 days' forcing) of peach cuttings ('Johnson Elberta') with the responses of other propagules after similar chilling treatments.

\begin{tabular}{llc}
\hline \hline Experiments & \multicolumn{1}{c}{ Measurements } & $\begin{array}{c}\text { Shoot } \\
\text { growth }\end{array}$ \\
\hline Seedlings & Shoot growth (17 days) & $0.80^{*}$ \\
& Lateral budbreak & $\underline{0.93}^{* * *}$ \\
& Leaf dry wt (64 days) & $\underline{0.98^{* * *}}$ \\
& Shoot dry wt & $\underline{0.97^{* * *}}$ \\
Initial seedling growth & Stem length (56 days) & $0.71^{* * *}$ \\
& Lateral shoot length & $-0.37^{\text {Ns }}$ \\
& Normal leaf area & $-0.69^{* * *}$ \\
& Abnormal leaf area & $0.71^{* * *}$ \\
Emergence & Percent (15 days) & $\underline{0.85^{* * *}}$ \\
Germination & Percent (10 days) & $\underline{0.92^{* * *}}$ \\
\hline
\end{tabular}

Days of forcing or growth in the greenhouse in parenthesis. Correlations for underlined values explained $>70 \%$ of the variability. ${ }^{\mathrm{NS}, * * * *}$ Nonsignificant or significant at $P=0.05$ or 0.001 , respectively. 

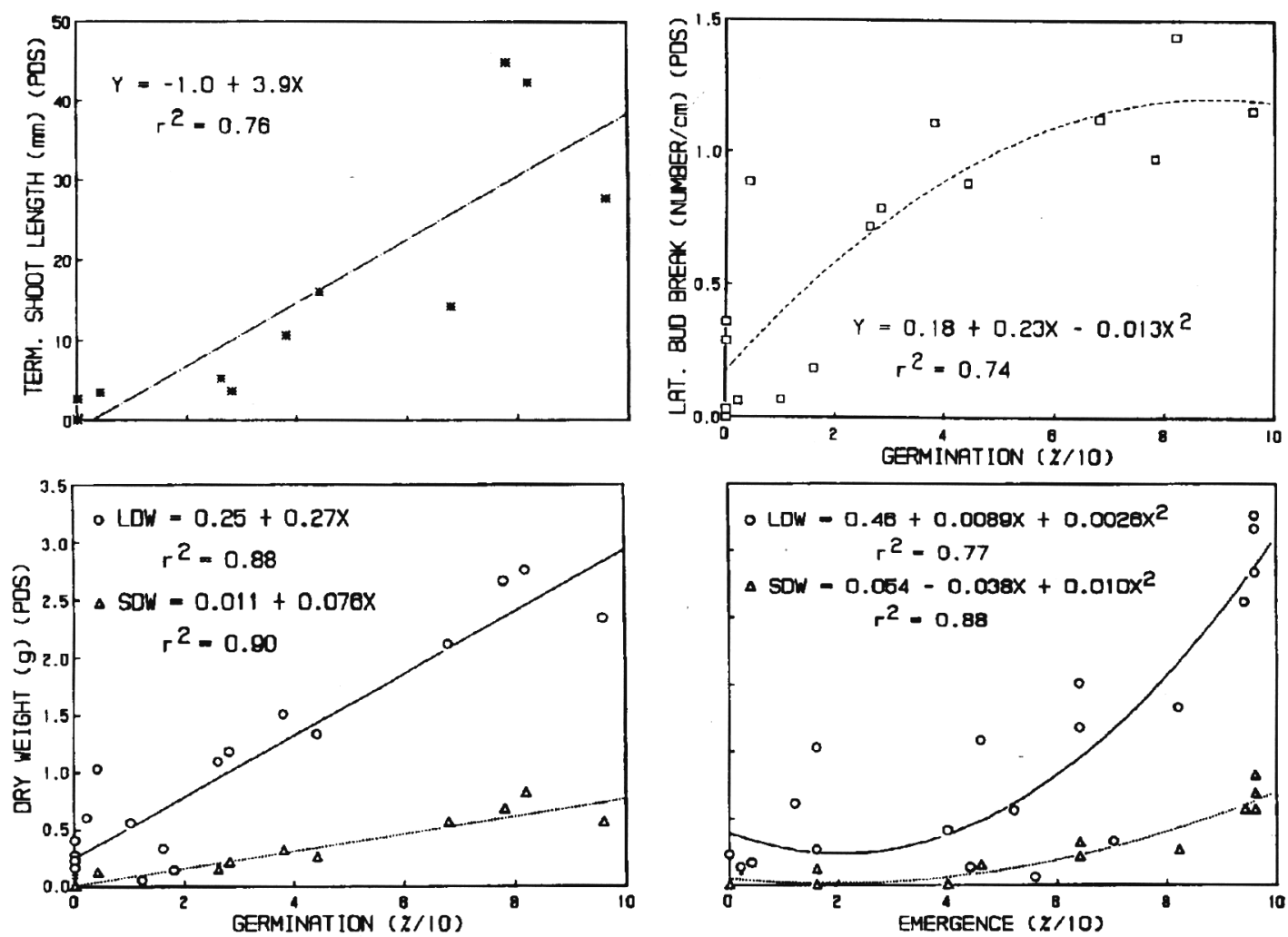

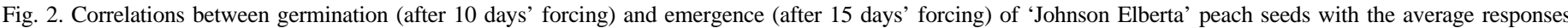

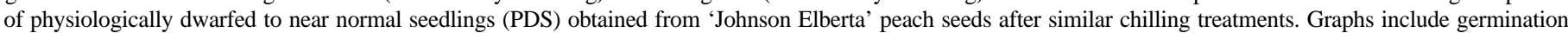
with terminal shoot growth and lateral budbreak (after 17 days' forcing) and leaf (LDW) and shoot dry weight [SDW (after 64 days of growth)] and emergence with leaf and shoot dry weight.
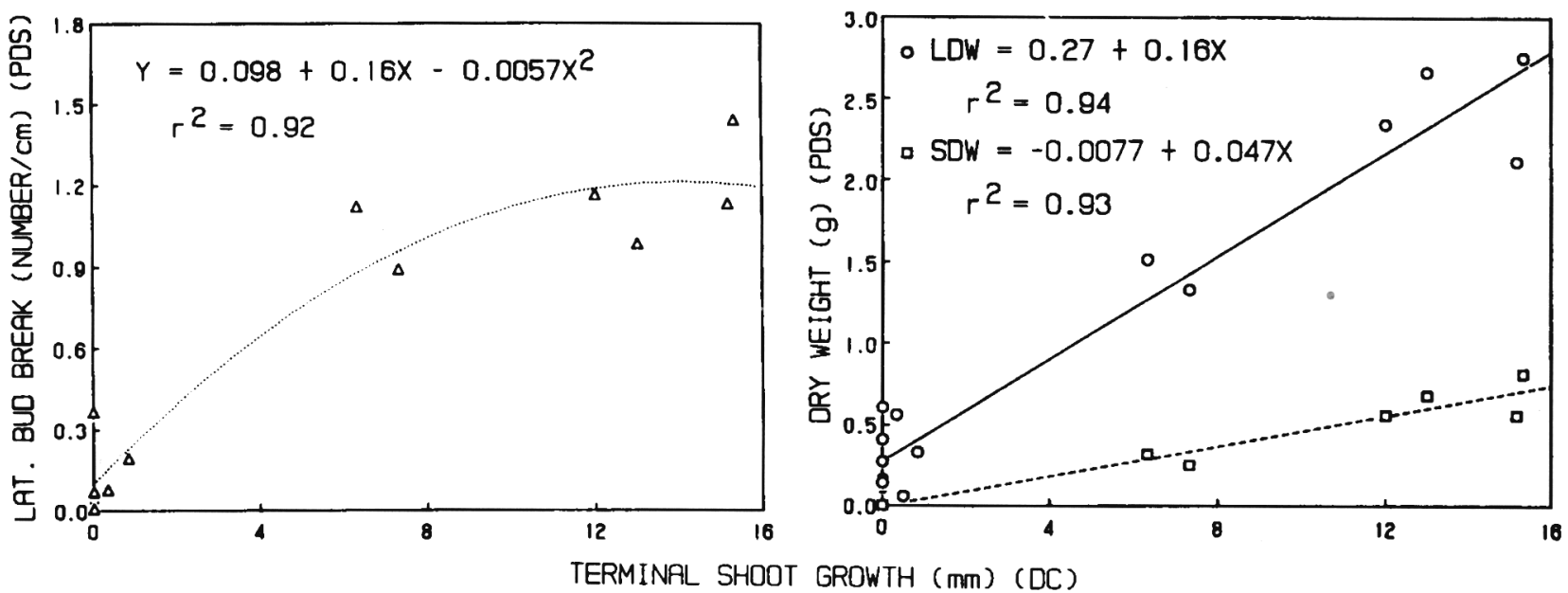

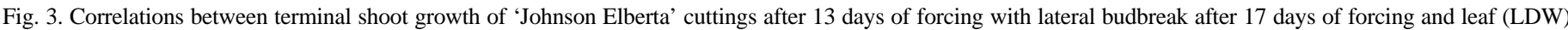

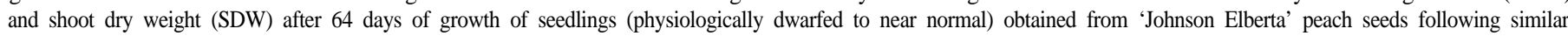
chilling treatments.

experiments as did terminal shoot growth ( 13 days of forcing) of cuttings (Table 4). These results suggest that terminal shoot growth might not be a good indicator of the chilling status of an intact mature plant.

In summary, germination had better and higher correlations with the other endodormant materials after similar chilling treatments than emergence or initial seedling growth. Therefore, germination was the best indicator of seed chilling for the overall peach chilling response. Shoot and leaf dry weights (56 days growth) correlated better than terminal shoot growth or lateral budbreak (17 days forcing) with the other endodormant materials after similar chilling treatments and, thus, were the best indicators of the chilling process for peach seedlings (second season). Terminal shoot growth (13 days forcing) of peach cuttings also correlated highly with germination, emergence, and seedling growth. Seeds, seedlings, andmature cuttings of 'Johnson Elberta' peach had similar responses to chilling. Therefore, their dormancy-release and growth-promoting mechanisms due to chilling are similar. However, the strength of the correlations depended on what was measured and when the results were taken during forcing 
or growth. The chilling requirement of 'Johnson Elberta' peach seeds, seedlings, and mature cuttings were higher than the chilling requirements of 'Elberta' peach flower buds.

\section{Literature Cited}

Chandler, W.H., M.H. Kimball, G.L. Philp, W.P. Tufts, and G.P. Weldon. 1937. Chilling requirements for opening of buds on deciduous orchard trees and some other plants in California. Univ. of California, Berkeley Bul. 611 .

Chang, S. and D.J. Werner. 1984. Relationship of seed germination and respiration during stratification with cultivar chilling requirement in peach. J. Amer. Soc. Hort. Sci. 109:42-45.

Davidson, O.W. 1934. Growing trees from 'non-viable' peach seeds. Proc. Amer. Soc. Hort. Sci. 32:308-312.

del Real-Laborde, J.I. 1987. Estimating chill units at low latitudes. HortScience 22:1227-1231.

Flemion, F. 1959. Effect of temperature, light and gibberellic acid on stem elongation and leaf development in physiologically dwarfed seedlings of peach and rhodotypos. Contrib. Boyce Thompson Inst. 20:57-70.

Frisby, J.W. and S.D. Seeley. 1993a. Chilling of endodormant peach propagules: I. Seed germination and emergence. J. Amer. Soc. Hort. Sci. 118:248-252.

Frisby, J.W. and S.D. Seeley. 1993b. Chilling of endodormant peach propagules: II. Initial seedling growth. J. Amer. Soc. Hort. Sci. 118:253257.
Frisby, J.W. and S.D. Seeley. 1993c. Chilling of endodormant peach propagules: III. Budbreak and subsequent growth of physiologically dwarfed to near normal seedlings. J. Amer. Soc. Hort. Sci. 118:258-262.

Frisby, J.W. and S.D. Seeley. 1993d. Chilling of endodormant peach propagules: IV. Terminal shoot growth of cuttings, including gibberellic acid treatments. J. Amer. Soc. Hort. Sci. 118:263-268.

Pasternak-Orawiec, G. and L.E. Powell. 1983a. Changes in abscisic acid and gibberellin during the stratification of low and high chilling apple seeds. HortScience 18:561. (Abstr.)

Pasternak-Orawiec, G. and L.E. Powell. 1983b. Chilling requirement for seeds of late-blooming apples. HortScience 18:561. (Abstr.)

Pollock, B.M. 1962. Temperature control of physiological dwarfing in peach seedlings. Plant Physiol. 37:190-197.

Richardson, E.A., S.D. Seeley, and D.R. Walker. 1974. A model for estimating the completion of rest for 'Redhaven' and 'Elberta' peach trees. HortScience 9:331-332.

Wang, D. and J. Beardow. 1968. Thermo-, photo-effect on rosaceous seeds during germination as expressed in subsequent seedling development. Contrib. Boyce Thompson Inst. 24: 17-23.

Weinberger, J.H. 1950. Chilling requirements of peach varieties. Proc. Amer. Soc. Hort. Sci. 56:122-128.

Weinberger, J.H. 1956. Prolonged dormancy trouble in peaches in the Southeast in relation to winter temperatures. Proc. Amer. Soc. Hort. Sci. 67:107-112.

Westwood, M.N. and H.O. Bjornstad. 1968. Chilling requirements of dormant seeds of 14 pear species as related to their climatic adaptation. Proc. Amer. Soc. Hort. Sci. 92:141-149. 